\title{
Psychological and pedagogical aspects of personnel training in higher inclusive education
}

\author{
Marina Skuratovskaya ${ }^{1, *}$ \\ ${ }^{1}$ Don State Technical University, 1, Gagarina, sq., 344003, Rostov-on-Don, Russia
}

\begin{abstract}
The article deals with the issue of professional training of students with disabilities in higher inclusive education. Statistical data showing the existing difficulties of obtaining higher education for disabled people are presented. The results of research on the material and technical, organizational, psychological and pedagogical conditions of accessibility of higher education for persons with disabilities are considered. The article analyzes the current pedagogical, socio-psychological and other barriers to training in higher inclusive education. The role of socio-psychological factors in the social adaptation of a disabled student in the educational space of the University is determined. Special attention is paid to psychological and pedagogical aspects of training in terms of inclusive higher education: designing integrated programmes of support for disabled students, the creation of the University rehabilitation-education environment, the definition of criteria for evaluation of universities on inclusive higher education. The article attaches great importance to the formation of an inclusive culture of an educational organization. Approaches to understanding inclusive culture presented in Russian and foreign studies are considered, and its component structure is described.
\end{abstract}

\section{Introduction}

One of the main trends in the development of education at the present stage is the creation of equal conditions for obtaining quality education for all citizens, regardless of their physical and mental development. This trend is evident in the development of inclusive education, including higher inclusive education. Inclusion in higher education reflects the principles of equality and humanism. Creating conditions for access to quality higher education for students with serious health problems is becoming an important task for any University today. After all, in accordance with the UN Convention on the rights of persons with disabilities, which was ratified by Russia in 2012, professional education is considered the most important condition for the implementation of the principle of independent life of a disabled person.

At the same time, statistics show that there are problems with obtaining higher education for the disabled. So, according to Rosstat, in 2019, Russian universities received 7.5 thousand students with disabilities. In total, about 23,000 students with disabilities were enrolled in higher education programs in 2019 . This is only $0.38 \%$ of all students studying

${ }^{*}$ Corresponding author: marinasku@yandex.ru 
in Russia. The number of students with disabilities is about 7 times less than among young people without disabilities. It is important that almost $25 \%$ of students with disabilities do not complete their studies, as evidenced by the monitoring conducted by "special opinion" together with members of the Public chamber with the support of the presidential Commission on disability of the Russian Federation.

The presented statistics show that there are serious problems in training personnel in the conditions of higher inclusive education. According to the preliminary analysis, these problems relate to various aspects of vocational training of disabled people-material, psychological, pedagogical, organizational, and have a negative impact on their access to higher education.

\section{Background}

Issues of accessibility of higher education have been the subject of research by many Russian scientists and scientists from around the world: S. V. Alyokhina, V. Z. Kantor, M. Skuratovskaya, I., Volodina, T. Klimova, Schwab, Andrea L. Ruppar, Theeratorn Lersilp, Beatriz Morgado Camacho, Rosario Lopez-Gavira, Anabel Moriña Díez and many others [1-5]. Attention to the criterion of accessibility of higher education is due to the understanding of disability from the position of its social model, according to which the obstacle to the successful inclusion of disabled people in society is considered not only the presence of persistent violations, but also psychological, pedagogical and environmental barriers.

Active productive life of a person with disabilities in this sense is provided through the creation of special conditions: specially organized training, education, a set of psychological and pedagogical tools aimed at the integral development of his personality within the limits of psychophysical capabilities.

Approaches to the organization of higher inclusive education in Russia were analyzed in detail ten years ago. Then the Union of rectors of Russia for the first time organized an interuniversity study on this problem. This study involved 214 universities in the country. It was noted that access to quality education for students with disabilities requires the development and implementation of a comprehensive program of educational support at the University. Such a program should include educational, socio-psychological, vocational guidance, material and technical and Wellness components. The study notes the importance of interaction with the business community for the formation of a local employment system that guarantees graduates with disabilities a stable base for full integration into society. Attention was drawn to the need for retraining of teachers aimed at mastering the competencies of working with students with disabilities and allowing them to take into account the features of students with disabilities in the educational process.

In the research of a number of scientists, special attention was paid to the importance of creating a rehabilitation and educational space at the University and individualizing the educational route of such students [6,7]. The rehabilitation and educational space involves a system of various activities, including patronage and social services, aimed at preparing students with disabilities for the maximum possible independent and independent life, social, labor and family adaptation. The importance of using special hardware techniques and psychological training, coping strategies is noted [5-7]. A number of works focused on the importance of overcoming existing intrapersonal and organizational barriers in teaching students with disabilities, their development of physical activity [8-10 ].

A number of studies have analyzed the requirements for special conditions that ensure accessibility of inclusive education at the University for students with hearing, vision, and musculoskeletal disorders. Among such requirements, in particular, were the use of assistive technologies, adaptive educational cases, the availability of information plates 
made in Braille, the provision of sign language interpreter assistance to students with hearing loss, architectural accessibility of University premises, special training in inclusive technologies for teachers, universal design of virtual spaces, etc. [4, 11-13]. Attention was also drawn to the availability of online training for disabled people [14]. Taking into account the active use of Internet technologies in the educational process, the conditions for supporting special educational needs of students with health disorders when using computer technologies were studied $[15,16]$.

Further research conducted in the direction of research on accessibility of higher inclusive education allowed scientists of the Nizhny Novgorod state pedagogical University named after K. Minin to identify criteria for evaluating the activities of universities in organizing inclusive higher education in 2016. These include criteria for evaluating the process and results of education. The criteria for evaluating the process of admission to higher education institutions were such factors as the availability and implementation of adapted educational programs, the organization of the educational process and educational process of students with disabilities, including through the support of students with disabilities by volunteers and the participation of students with disabilities in sports competitions and cultural events. The result of higher inclusive education was proposed to be evaluated by the criterion of the number of employed graduates with disabilities.

Interesting are the data presented in the work of Beatriz Morgado Camacho, Rosario Lopez-Gavira, Anabel Moriña Díez, revealing the perception of Spanish students with disabilities about the quality of the educational environment. These included physical accessibility for all, participatory teaching methods and the use of numerous technological resources, positive attitudes on the part of the teaching staff regarding disability, and specific academic training in the field of disability and new technologies [5].

From a psychological point of view, the educational environment that really contributes to the integration of students with disabilities into the educational space of the University is a complex system of subject-subject relations aimed at maintaining an open constructive dialogue. The content of the dialogue in this context implies a unity of attitudes, ideas about the opportunities and difficulties of all parties involved in it.

With regard to the organization of the educational environment for students with disabilities, this means the need for systematic work on psychological and pedagogical education of teachers and staff of the University, as well as psychological support for students with disabilities themselves in order to eliminate the consequences of negative experiences, undesirable attitudes, and self-doubt. And such negative attitudes are not only on the part of students, but also on the part of teachers. They are the essence of sociopsychological barriers that have a negative impact on the development of a disabled student's personality and social adaptation.

Social adaptation is considered both as a process of adaptation to the conditions of the social environment, and as a result of this process. It should be taken into account that social adaptation can and should become a driving force for the development of a disabled student. The educational environment can act as a driving force in the development of a student with a disability only if he is perceived by others as an active subject in building an educational and life trajectory, having responsibility and the ability to make informed choices, able to overcome difficulties encountered on the way. With this approach, the educational environment should be focused primarily not on disorders in psychophysical development, but on the fullest realization of the internal potential of a student with a disability.

If the educational environment when a disabled student receives higher education is focused on the existing defect and is aimed at eliminating any external barriers, it will contribute to the formation of a passive, dependent position, the formation of psychological dependence on others. Excessive assistance and simplification of tasks, full availability of 
teachers with any minimal difficulty negatively affects the personal development of a disabled student. This situation leads to the appearance of students ' attempts to subdue the time of teachers and other students, orientation to constant help, conflict, the desire to simplify the situation for themselves to solve educational tasks at the expense of others. Thus, we can distinguish another criterion in the assessment of higher inclusive education the criterion of activity of its main subjects-students with disabilities.

An important role in shaping the activity of students with disabilities is the attitude of teachers and fellow students - their immediate environment. In a number of studies, it is noted that in the course of interaction with a disabled person, University teachers often try to reduce the complexity of speech turns, finish a conversation with them faster, and Express an opinion that is close to the opinion of a student with a disability.

These facts demonstrate the need to create an inclusive culture. The formation of an inclusive culture is one of the most important conditions for the effectiveness of teaching activities in the context of inclusive higher education. An inclusive culture is the Foundation for creating an accessible, safe and comfortable educational environment for students with disabilities. For this purpose, many works discuss the attitude of teachers to students with disabilities and their readiness to help overcome emerging stressful situations $[17,18]$.

The concept of inclusive culture, as noted by A. Yu. Semenov, N. T. Popov, A. S. Kusevska, based on the social model of disability implies the right of everyone to equal access to education, the need to address the special cultural needs of persons with disabilities and the elimination of all kinds of barriers to the implementation of this law. Achieving equal educational opportunities V. N. Yarskaya-Smirnova, Carmen CosteaBărluţiu, Alina S. Rusu is associated, in particular, with the dissemination of inclusive values and norms of relationships with people with disabilities, which allow for a real understanding[18]. Similar views are expressed by Andrea L. Ruppar And V. N. Ponikarova[3]. Studying the readiness of teachers for inclusive education, they draw attention to the presence of value, motivational and emotional attitude of teachers to inclusion, which is implemented through the typology of coping behavior in professional activities, they note. At the same time, the authors note the influence of the level of pedagogical knowledge about the special educational needs of students with disabilities and existing stereotypes regarding the understanding of the capabilities of disabled people. [3].

The normative aspect of creating an inclusive culture in the organization is considered by P. V. Romanov And V. V. Yakovleva. The authors draw attention to the importance of special rules, norms, and measures that allow creating an environment in which each person is perceived as a value, regardless of their characteristics.

In V. V. Khitruk's research, the concept of inclusive culture is defined as an integrative personal quality formed in stages. Inclusive culture, as a personal quality, includes a system of certain knowledge, social, personal and professional competencies that allow you to be successful in an inclusive educational space. It manifests itself, as noted by Carmen CosteaBărluţiu, Alina S. Rusu, not only in a certain system of accepting inclusive values and implementing inclusive practices, but also in the ability to be open to communication and change, and in the willingness to accept others, even if they are different [18].

In this approach the notion of inclusive culture close to the notion of tolerance, which is regarded as an important component of an inclusive culture as integrative personal education, reflected in a positive rating and accept himself and the other, the absence of bias in the assessment of the internal features, capabilities and behavior of individuals with different levels of psychophysical development, the ability to establish friendly relations and cooperation with others, regardless of the characteristics of their development [Skuratovskaya, Volodin]. 
The paper by A. B. Orlov and A. Z. Shapiro presents the process of forming tolerance in accordance with the three types of tolerance identified by the author.

These types to a certain extent reflect the logical and temporal sequence of the formation of tolerance in the process of personal development.

Table 1. Types of tolerance.

\begin{tabular}{|l|l|l|}
\hline № & \multicolumn{1}{|c|}{ Types of tolerance. } & \multicolumn{1}{c|}{ The essence types of tolerance } \\
\hline 1 & Natural tolerance & openness, trustfulness, natural acceptance of the other \\
\hline 2 & $\begin{array}{l}\text { External moral } \\
\text { tolerance }\end{array}$ & $\begin{array}{l}\text { the desire to restrain oneself using psychological defense } \\
\text { mechanisms, to hide internal intolerance, increasing tension, } \\
\text { unspoken disagreement, suppressed aggression (quasi- } \\
\text { tolerance) }\end{array}$ \\
\hline 3 & Internal moral tolerance & $\begin{array}{l}\text { a person's acceptance of both others and himself, interaction } \\
\text { with the external and internal world in a receptive, dialogical } \\
\text { manner, respect for values and meanings that are significant for } \\
\text { another, and awareness and acceptance of their own inner } \\
\text { world, their own values and meanings, goals and desires }\end{array}$ \\
\hline
\end{tabular}

In psychological and pedagogical research on social and educational inclusion, attempts are made to identify and describe the component structure of inclusive culture. Thus, in the work of I. A. Turchenko, 4 structural components of inclusive culture are identified.

Table 2. Structural components of an inclusive culture.

\begin{tabular}{|c|c|}
\hline Component & Component characteristics \\
\hline $\begin{array}{c}\text { motivational and value } \\
\text { component }\end{array}$ & $\begin{array}{c}\text { the teacher's acceptance of inclusive values as the basis of } \\
\text { their teaching activities }\end{array}$ \\
\hline cognitive component & $\begin{array}{c}\text { system of knowledge theory and methods of inclusive } \\
\text { education }\end{array}$ \\
\hline activity component & $\begin{array}{c}\text { availability of practical skills and practical experience in } \\
\text { the field of inclusive education }\end{array}$ \\
\hline the reflective component & $\begin{array}{c}\text { ability to critically analyze their teaching activities and } \\
\text { their results in order to further improve them }\end{array}$ \\
\hline
\end{tabular}

Studies of the essential characteristics and structural features of inclusive culture have led to the fact that in recent years, the inclusive culture of an educational organization is interpreted as a complex, multidimensional phenomenon. The diversity of inclusive culture is shown in the fact that it is considered as a special philosophy, part of the General school culture, aimed at promoting the values of inclusion, a unique microclimate of trust, a special inclusive atmosphere.

At the same time, specially conducted research aimed at studying the features of inclusive culture of teachers of educational organizations, including University teachers, showed disappointing results. The study of inclusive culture considered the values and norms of inclusion, readiness to interact in inclusion, awareness of the need for new knowledge and skills, and social responsibility for the results of inclusion to identify. The authors found that a significant part of the surveyed teachers have an extremely low level of inclusive culture. [18]. The results of the study also showed that among University teachers, the most active and highly motivated are those teachers who have had a positive experience of social or educational inclusion, who in their personal experience or life have had the opportunity to interact with people with disabilities and help include people with 
disabilities in Society, Education and life, who are interested in developing their competencies.

\section{Conclusion}

Our analysis of psychological and pedagogical aspects of personnel training in the system of higher inclusive education has shown the undoubted relevance of this problem. Modern research studies consider organizational issues of accessibility of inclusive education providing architectural accessibility, educational and socio-psychological support for students with disabilities, including them in sports and cultural events. But an equally important aspect is the readiness of University teachers for inclusive education, the formation of an inclusive culture in the educational organization of higher education. The essence of inclusive culture and its content structure are studied in scientific works. The criteria for evaluating the formation of an inclusive culture among teachers are defined. At the same time, the level of inclusive culture among University teachers is very differentiated. Along with University teachers who have a high level of inclusive culture, a significant number of University teachers demonstrate a critical level of inclusive culture. These results indicate the need for serious work to create an inclusive environment in higher education institutions, and also emphasize the special importance of developing an inclusive culture of higher education.

\section{References}

1. M. Skuratovskaya, I. Volodina, T. Klimova, MEJSR 16(10), 1441-1445 (2013)

2. A. Schwab, RDD 62, 160-165 (2017)

3. A.L. Ruppar, TTE 67, 114-124 (2017)

4. T. Lersilp, PES 36, 61-64 (2016)

5. B. Morgado Camacho, R. Lopez-Gavira, A. Moriña Díez, IJ ER 85, 148-156 (2017)

6. R. Gabriely, R. Tarrasch, M. Velicki, Z. Ovadia-Blechman, RDD 100, 103630 (2020)

7. $\mathrm{Na} \mathrm{Xu,} \mathrm{Yingyi} \mathrm{Liu,} \mathrm{DHJ} \mathrm{13/1,} 100830$ (2020)

8. J. Úbeda-Colomer, J. Devís-Devís, C.H.P. Sit, DHJ 12/2, 278-286 (2019)

9. J. Úbeda-Colomer, K.A. Martin Ginis, J. Monforte, V. Pérez-Samaniego, J. DevísDevís, DHJ 12/4, 574-580 (2019)

10. J. Úbeda-Colomer, J. Monforte, J. Devís-Devís, PH 166, 69-78 (2019)

11. R. Lopez-Gavira, A. Moriña, N. Melero-Aguilar, V. Hugo Perera-Rodríguez, PSBS 228, 175-182 (2016)

12. A. Brizee, M. Sousa, D. Lynn Driscoll, CC 29/4, 341-366 (2012)

13. I. Dahlstrom-Hakki, Z. Alstad, M. Banerjee, CE 150, 103842 (2020)

14. M.R. Snodgrass, M. Israel, G.C. Reese, CE 100, 1-17 (2016)

15. J.C. Wright, V.F. Knight, E.E. Barton, RASD 70, 101476 (2020)

16. G. Michael Mu, Y. Hu, Y. Wang, TTE 67, 125-134 (2017)

17. C. Costea-Bărluţiu, A.S. Rusu, PSBS 2093, 572-579 (2015) 